TITLE:

\title{
The effects of cardioactive drugs on cardiomyocytes derived from human induced pluripotent stem cells
}

\section{AUTHOR(S):}

Yokoo, Noritaka; Baba, Shiro; Kaichi, Shinji; Niwa, Akira; Mima, Takahiro; Doi, Hiraku; Yamanaka, Shinya; Nakahata, Tatsutoshi; Heike, Toshio

\section{CITATION:}

Yokoo, Noritaka ...[et al]. The effects of cardioactive drugs on cardiomyocytes derived from human induced pluripotent stem cells. Biochemical and Biophysical Research Communications 2009, 387(3): 482-488

\section{ISSUE DATE:}

2009-09

URL:

http://hdl.handle.net/2433/85222

\section{RIGHT:}

c 2009 Elsevier Inc. All rights reserved.; この論文は出版社版でありませ ん。引用の際には出版社版をご確認ご利用ください。; This is not the published version. Please cite only the published version. 
The effects of cardioactive drugs on cardiomyocytes derived from human induced pluripotent stem cells

Noritaka Yokoo $^{\text {a }}$, Shiro Baba ${ }^{a}$, Shinji Kaichi ${ }^{a}$, Akira Niwa ${ }^{a}$, Takahiro Mima ${ }^{a}$, Hiraku Doi ${ }^{a}$, Shinya Yamanaka $^{\mathrm{b}}$, Tatsutoshi Nakahata ${ }^{\mathrm{b}}$, Toshio Heike ${ }^{\mathrm{a} *}$

${ }^{a}$ Department of Pediatrics, Graduate School of Medicine, Kyoto University, 54 Kawahara-cho, Shogoin, Sakyo-ku, Kyoto 606-8507, Japan

${ }^{\mathrm{b}}$ Center for iPS Cell Research and Application (CiRA), Institute for Integrated Cell-Material Sciences, Kyoto University, 53 Kawahara-cho, Shogoin, Sakyo-ku, Kyoto 606-8507, Japan

\section{*Corresponding author}

Name:Toshio Heike MD, PhD

Address: Department of Pediatrics, Graduate School of Medicine, Kyoto University, 54

Kawahara-cho, Shogoin, Sakyo-ku, Kyoto, 606-8507, Japan.

Telephone: +81-75-751-3295

Fax: +81-75-752-2361

E-mail: heike@kuhp.kyoto-u.ac.jp 


\section{Abstract}

Developing effective drug therapies for arrhythmic diseases is hampered by the fact that the same drug can work well in some individuals but not in others. Human induced pluripotent stem (iPS) cells have been vetted as useful tools for drug screening. However, cardioactive drugs have not been shown to have the same effects on iPS cell-derived human cardiomyocytes as on embryonic stem (ES) cell-derived cardiomyocytes or human cardiomyocytes in a clinical setting. Here we show that current cardioactive drugs affect the beating frequency and contractility of iPS cell-derived cardiomyocytes in much the same way as they do ES cell-derived cardiomyocytes, and the results were compatible with empirical results in the clinic. Thus, human iPS cells could become an attractive tool to investigate the effects of cardioactive drugs at the individual level and to screen for individually tailored drugs against cardiac arrhythmic diseases.

Keywords: Human induced pluripotent stem cell, Human embryonic stem cell, Cardiomyocytes,

Drug loading test, and Arrhythmia 


\section{Introduction}

The long-QT syndrome (LQTS) is characterized by an abnormal prolongation of the QT-interval on the ECG and an increased risk of sudden death, due to ventricular fibrillation known as Torsade de Pointes (TdP) [1]. In a previous study [2], four patients died suddenly (1.3\% per year) during an average follow-up period of 26 months per patient and among 196 idiopathic LQTS patients, 27 experienced one or more syncopal episodes ( $8.6 \%$ per year). Molecular genetic studies have revealed several forms of congenital LQTS caused by mutations in genes coding for potassium, sodium and calcium channels or membrane adapters [3-6]. Preliminary clinical studies have since suggested the feasibility of performing genotype-specific therapy with therapeutic agents that abbreviate the QT-interval [7]. But it is difficult to select the correct drug because within the same LQTS subtype, the same drug can sometimes have different effects depending on the patient.

Furthermore, the diagnosis of LQTS subtypes is difficult. Genetic testing can only identify $50-75 \%$ of probands [8]. So an epinephrine challenge is needed in some patients to diagnose LQTS in a clinical setting [9]. However, this test sometimes induces TdP, so it must be done under careful patient surveillance.

The generation of iPS cells from human fibroblast using a combination of 4 transcription factors $(O c t 3 / 4$, Sox2, Klf4, and $c-M y c)$ has opened remarkable new avenues for not only basic research but 
also regenerative medicine, understanding of disease mechanisms, drug screening, and toxicology

[10]. A recent study reported the generation of disease-specific iPS cell lines from patients with a variety of diseases [11]. If patient-specific iPS cells could be commonly generated and employed in a clinical setting, they could become a useful tool for selecting the best drug for individual LQTS patients.

But there has been no report that cardiomyocytes derived from human iPS cells respond to drugs in the same way as human cardiomyocytes. It is important to investigate whether cardiomyocytes derived from human iPS cells react to drugs in the same way as human cardiomyocytes, if patient-specific iPS cells are to be used in a clinical setting for drug screening. Previous studies have hinted that some drugs produce the same effects in cardiomyocytes as in cardiomyocytes derived from ES cells [12-14]. In this study, we investigated whether cardiomyocytes derived human iPS cells responded to drugs in the same way as in cardiomyocytes derived from human ES cells with respect to beating frequency and contractility, and we compared these results with previously described clinical empirical results [15]. 


\section{Materials and methods}

Human iPS and human ES cell culture.

We used human ES cell line, KhES1, and human iPS cell lines 201B7. Human iPS cells and human ES cells were maintained on mitomycin-C (Kyowa Hakkoh) treated mouse embryonic fibroblasts (MEFs) or SNLs on cell culture dishes. In brief, both human iPS and human ES cells were maintained in DMEM/F12 culture medium (SIGMA) supplemented with 20\% knock-out serum replacement (Gibco), $0.1 \mathrm{mmol} / \mathrm{L}$ nonessential amino acids (Gibco), 4 mmol/L L-glutamine, 0.8 $\mu \mathrm{mol} / \mathrm{L}$ basic fibroblast growth factor (bFGF) (Invitrogen).

\section{Embryoid body formation and cardiac differentiation}

Colonies were detached from cell culture dishes by incubating them with PBS containing $0.25 \%$ trypsin (Gibco) and $1 \mathrm{mg} / \mathrm{mL}$ collagenase I (Worthington) at $37^{\circ} \mathrm{C}$ for $3-4 \mathrm{~min}$. The cells were then placed in petri dishes (Sterilin) in suspension cultures for 7 days with maintenance medium supplemented with $5 \mathrm{ng} / \mathrm{ml}$ bFGF. Embryoid bodies (EBs) were then plated on $0.1 \%$ gelatin-coated 6-well culture plates (BD Biosciences) and cultured in cardiac differentiation medium, consisting of alpha MEM (Gibco) supplemented with $0.5 \mu \mathrm{mol} / \mathrm{L} 2 \mathrm{ME}$ and 10\% FCS (Hyclone) (changed once every 7 days). Contractile colonies appeared 15-25 days after plating on gelatin-coated dishes. 
(Fig.1A).

Reverse transcriptase polymerase chain reaction (RT-PCR).

Total RNA was isolated using TRIzol Reagent (Invitrogen) from undifferentiated iPS cells, EBs derived from human iPS cells, the contracting areas of differentiated human iPS cells, and human right ventricular tissue (obtained by a tetralogy of Fallot patient that had received a right flow, ventricular tract ventriculotomy). Total RNA was used for oligo (dT) 12-18-primed reverse transcription using the Super Script II First-Strand Synthesis System (Invitrogen). RT-PCR was carried out using Ex Taq (TAKARA BIO). PCR conditions included denaturation at $94^{\circ} \mathrm{C}$ for $30 \mathrm{~s}$, annealing at $60^{\circ} \mathrm{C}$ for $30 \mathrm{~s}$, and extension at $55-65^{\circ} \mathrm{C}$ for 1 min for $25-35$ cycles, with a final extension at $72^{\circ} \mathrm{C}$ for $7 \mathrm{~min}$. Primers used are listed in Table 3 .

\section{Immunohistochemistry}

Contractile colonies were partitioned into small particles using collagenase I (Worthington) for $2 \mathrm{~h}$ at $37^{\circ} \mathrm{C}$. The cells were then washed and plated on 6 -well culture plates coated with $0.1 \%$ gelatin for 2 or 3 days to allow attachment. Cells were fixed in $4 \%$ paraformaldehyde for $15 \mathrm{~min}$ at $4{ }^{\circ} \mathrm{C}$. Then the cells were incubated with primary antibodies, such as polyclonal anti-cardiac Troponin I (IgG, 1:50 dilution; Santa Cruz Biotechnology), polyclonal anti-MLC2v (IgG, 1:50 dilution; Santa Cruz 
Biotechnology), or polyclonal anti-ANP (IgG, 1:250 dilution; Chemicon) in 2\% skim milk with

$0.1 \%$ Triton X-100 overnight at $4{ }^{\circ} \mathrm{C}$. Secondary antibodies were cyanine 3 (Cy3)-conjugated donkey anti-rat IgG (1:200 dilution; Jackson Immunoresearch), Cy3-conjugated donkey anti-rabbit IgG (1:200 dilution; Jackson Immunoresearch), and Cy3-conjugated donkey anti-goat IgG (1:200 dilution; Jackson Immunoresearch). Nuclei were counter-stained with Hoechst 33342 (Molecular probes).

\section{Electrophysiological examination}

Microelectrode arrays analysis was performed to investigate the electrophysiological potential of cardiomyocytes derived from human iPS cells using the MED 64 system (Alpha MED Sciences) [16-18]. Micro-dissected contracting areas were plated on MED-probe dishes (Alpha MED Sciences) followed by incubation for 3-7 days to allow attachment. The potentials of the contractile colonies derived from these cells were then recorded.

Drug loading test

Differentiation medium was replaced with alpha MEM containing $10 \mathrm{mmol} / \mathrm{L}$ HEPES buffer

(Nacalai tesque), $7 \mathrm{~mol} / \mathrm{L} \mathrm{NaCl}$, and $0.5 \mu \mathrm{mol} / \mathrm{L} 2 \mathrm{ME}$, which was adjusted to $\mathrm{pH} 7.4$ with $\mathrm{NaOH}$.

After 10 min incubation at $37^{\circ} \mathrm{C}$, the frequency and contractility of the contractile colonies were 
measured in a movie recorded by a VB 7000 (KEYENCE) camera under drug-free medium

conditions as well as under drug conditions with three different drug concentrations. Beating

colonies were selected when the beating rate was $40 / \mathrm{min}$ to $60 / \mathrm{min}$ under drug-free medium

conditions. Colonies whose contractile motion was distended were excluded. Loading drugs were as follows; isoproterenol (SIGMA), adrenaline (Dai-ichi Sankyo), propranolol (SIGMA), procainamide (Dai-ichi Sankyo), mexiletine (Boehringer Ingelheim), flecainide (Eisai), verapamil (SIGMA), and amiodarone (Sanofi-aventis).

Analysis of beating rate and contractility

Beating rates were counted based on the video recordings. Recently, some papers reported that video-edge detecting systems are useful for calculating the contractility of contractile colonies [12]. We imitated this method and calculated the contractility of colonies. In brief, we extracted the still images of systolic phase and diastolic phase from the recorded video images. The major axis of each phase was measured and the contractile index was defined as $a-b / a$ ( $a$ : length of diastolic phase, $b$ : the length of systolic phase) (Fig.4A).

\section{Statistics}

Data are presented as means \pm SEM. Statistical significance was determined by the unpaired $t$-test 
for two samples and one-way ANOVA followed by the Scheffe test for more than three samples. $P$ values $<0.05$ were considered to be statistically significant. 


\section{Results}

Time course analysis of gene expression during cardiac differentiation

First, we examined the time course of gene expression during cardiac differentiation of human iPS

cells by RT-PCR to compare it with that of normal embryogenesis (Fig.1B). Undifferentiated human

iPS cells strongly expressed endogenous Oct4 and Sox2, which are undifferentiated cell markers, but

did not express the mesodermal marker Brachyury or the cardiac progenitor marker TBX5 (Fig. 1B).

$K D R$ was weakly expressed. These results show that undifferentiated human iPS cells have similar

properties to undifferentiated human ES cells [19]. Endogenous Oct4 and Sox2 expression gradually

decreased during culture in differentiation medium. The expression of the mesodermal marker

Brachyury increased from day 10 after EB formation. The expression of $K D R$ also gradually

increased from day 10 after EB formation. These patterns of mesodermal marker expression are

compatible with those of human ES cells as previously described [19]. The cardiac progenitor

marker $T B X 5$ was expressed from day 20 after EB formation, which is compatible with the gene

expression patterns seen during cardiac formation in embryogenesis and human ES cell

differentiation as previously described [19]. The result additionally suggests that human iPS cells

differentiated into the mesodermal lineage and then differentiated into contractile colonies via 
cardiac progenitor cells.

Cardiac differentiation of human iPS cells via EBs

Next, we examined the contractile colonies consisting of cardiac-specific cells. Contractile colonies were observed from 15 to 25 days after EB formation both in human iPS and human ES cell populations. This result demonstrates that our differentiation methods could generate contractile colonies from both human iPS cells and human ES cells. Next, we investigated whether these contractile colonies were human cardiomyocytes. For this purpose, we carried out RT-PCR and examined for the expression of cardiac cell markers. RT-PCR showed that contractile colonies expressed cardiac markers $N k x 2.5, M E F 2 c, M L C 2 a$, and $M Y H C B$ (Fig.2A). Moreover, we carried out immunohistochemical analysis to confirm that the contractile colonies were human cardiomyocytes. Contractile colonies were stained by the cardiac cell marker, cTnI, the ventricular cell marker, MLC2v, and the atrial cell marker, ANP. The colonies were also stained by cTnI, and some of them were stained by MLC2v or ANP (Fig.2C-E). These results of immunohistochemical analysis confirmed that the contractile colonies were indeed human cardiomyocytes.

\section{Electrical analysis of contractile colonies}

To investigate whether the contractile colonies that expressed cardiac markers were electrically 
functional cardiac colonies, we measured their electrical potentials by microelectrode array analysis using the MED 64 system (Alpha MED Sciences) [16-18]. The field potentials of the contractile colonies were comparable to those of cardiomyocytes derived from human ES cells as previously reported (Fig 2F) [16-18]. Moreover, RT-PCR showed that these cells expressed the If channel (HCN4), the L-type calcium channel (CACNA1C), the sodium channel (SCN5A), the inward rectifier (Kir2.1), the transient outward channel (Kv4.3), and the delayed rectifier $\operatorname{IKr}(H E R G)$ (Fig 2B). Effects of drugs on the beating frequency of cardiomyocytes derived from human iPS cells We next investigated whether the cardiomyocytes derived from iPS cells reacted with cardioactive drugs in the same manner as cardiomyocytes derived from human ES cells by performing drug loading tests. First we compared the beating frequencies of these two cell populations. A total of eight drugs were tested (see Table 1 for the list of drugs and their concentrations). The $\beta$ stimulants, adrenaline and isoproterenol increased beating frequency in a dose dependent manner. The beta blocker, propranolol, and the Na channel blockers, procainamide, mexiletine, and flecainide had no effect on beating frequency. The Ca channel blocker verapamil decreased beating frequency in a dose dependent manner, and all contractile colonies ceased to contract when $1 \times$ $10^{-5} \mathrm{M}$ verapamil was loaded. Amiodarone, which mainly acts as a $\mathrm{K}$ channel blocker, decreased beating frequency in a dose dependent manner. We carried out $\beta$ blocker loading in the presence 
of $1 \times 10^{-6} \mathrm{M}$ isoproterenol in order to mimic conditions in vivo [20]. Under this condition, the beating frequency decreased in a dose dependent manner. There were no statistical differences between the drug concentrations required to elicit the effects in human iPS cells and those required to elicit the effects in cardiomyocytes derived from human ES cells (Fig.3). Previous reports showed that some drugs had similar effects on the beating frequency of cardiomyocytes derived from ES cells and on bone-fide human cardiomyocytes, suggesting that human iPS cells and cardiomyocytes respond similarly to these drugs as well [12-14]. Table 2 shows a comparison of the effects of drug loading on human iPS cells and the effects of these drugs in a clinical setting [15]. As the effects are broadly similar and occur within the same range of drug concentrations, we conclude that cardiomyocytes derived from human iPS cells are a good model for testing the effects of drugs on the beating frequency of human cardiomyocytes. The results are also compatible with previously reported clinical empirical results [15].

The effects of drugs on the contractility of cardiomyocytes derived from human iPS cells

Next, we investigated the effects of drugs on the contractility of human iPS cells and cardiomyocytes derived from human ES cells. The results showed that adrenaline and isoproterenol increased contractility in a dose dependent manner. Propranolol, mexiletine, or amiodarone had no effect on contractility. Verapamil decreased contractility in a dose dependent manner, and all contractile 
colonies ceased to contract when $1 \times 10^{-5} \mathrm{M}$ verapamil was loaded. Procainamide and flecainide also decreased the beating frequency in a dose dependent manner. We also carried out $\beta$ blocker loading in the presence of $1 \times 10^{-6} \mathrm{M}$ isoproterenol with cardiomyocytes derived from human iPS cells, which showed that contractility again decreased in a dose dependent manner under these conditions. There were no statistical differences between the drug concentrations required to elicit the effects in human iPS cells and those required to elicit the effects in cardiomyocytes derived from human ES cells (Fig.4B). Previous reports have shown that some drugs had similar effects on the beating frequency of cardiomyocytes derived from ES cells and on bone-fide human cardiomyocytes, suggesting that human iPS cells and cardiomyocytes respond similarly to these drugs as well [12].

The results were compatible with clinical empirical results [15]. So we conclude that cardiomyocytes derived from human iPS cells respond similarly to drugs that affect contractility in human cardiomyocytes. 


\section{Discussion}

In this report, we differentiated human iPS cells into cardiomyocytes, and compared the effects of drugs on cardiomyocytes derived from these cells and on cardiomyocytes derived from human ES cells, as well as with empirical results obtained in a clinical setting. The time course analysis of gene expression during cardiac differentiation was compatible to that seen during cardiogenesis of normal embryogenesis, and the results of the drug loading tests showed that cardiomyocytes derived from human iPS cells responded to drugs in much the same way as cardiomyocytes derived from human ES cells. The results were also compatible to empirical results obtained in a clinical setting.

Human iPS cells can be generated from somatic cell by introducing transcriptional factors. This technology is expected to generate patient-specific iPS cells suitable for the study of disease mechanisms, drug screening, and toxicology studies. This technology is easier to implement for the generation of patient-specific pluripotent cells than current technology which relies on nuclear transplantation technology to generate patient-specific pluripotent cells from ES cells. If cardiomyocytes derived from iPS cells could be shown to respond to drugs in the same way as human derived cardiomyocytes, then this technology would also constitute a major advance because it would allow the use of patient-specific iPS cell for the screening of patient-specific drugs against 
arrhythmic diseases, especially for lethal arrhythmic diseases such as LQTS where it is often very

difficult to select for the best drug.

As the generation of cardiomyocytes from human iPS cells relies on the introduction of exogenous genes, we addressed the troublesome issue of whether cardiomyocytes derived from human iPS cells would respond to drugs in the same way as normal human cardiomyocytes. We considered the beating frequency and contractility to be very important indicators, because heart pump function is defined by beating frequency and contractility. So we investigated the effects of drugs on these two indicators, and found that drugs affect the beating frequency and contractility of cardiomyocytes derived from human iPS cells in much the same way as they do in a clinical setting. This result suggests that cardiomyocytes derived from human iPS cells could be used for drug screening tests instead of current screening procedures in a clinical setting. Cardiomyocytes derived from ES cells also responded to drugs in the same way as cardiomyocytes derived from human iPS cells.

Thus, these results suggest that patient-specific iPS cells could be used to select for the best drug to treat arrhythmic disease at the individual level, and would have the additional advantage of allowing the massive and rapid screening of drugs at concentrations that would be normally prohibitive in patients. However, until further studies are carried out, it is probably still too early to conclude that the drug effects on human iPS cell lines and patients are identical.

In conclusion, cardiomyocytes derived from human iPS cells have tremendous potential for drug 
screening, which should open the possibility of using patient-specific iPS cells in a clinical setting.

The best drugs could be selected safely and rapidly by using human iPS cells from individual patients. 


\section{Figure Legends}

Fig. 1 An outline of the protocol used for the differentiation of human iPS cells and human ES cells.

Scale bars $=200 \mu \mathrm{m}$ (A) Time course analysis of immature gene expression, mesodermal markers, and cardiac progenitor markers during differentiation (B).

Fig. 2 Gene expression analyses of cardiac markers by RT-PCR (A). Gene expression analysis of ion channel related genes (B). Immunohistochemistry of contractile colonies. Colonies were stained with cTnI (C), MLC2v (D), or ANP (E). Scale bars $=100 \mu \mathrm{m}$. Field potentials of contractile colonies measured by the MED 64system (F).

Fig.3 The effects of cardioactive drugs on the beating rates of contractile colonies derived from human iPS cells and human ES cells. Adrenaline, isoproterenol, verapamil, amiodarone, and isoproterenol+propranolol had statistically significant effects between pre drug loading and the maximum concentration of the drug used in cardiomyocytes derived from human iPS cells $(P<0.05)$. There were no statistically significant differences between the concentrations of drugs that elicited effects in human iPS cells and those that elicited effects in human ES cells. 
Fig.4 Calculation of the contractility index. Right panel; diastolic phase, left panel; systolic phase.

Scale bars $=200 \mu \mathrm{m}(\mathrm{A})$. The effect of cardioactive drugs on the contractility of contractile colonies derived from human iPS cells and human ES cells. Adrenaline, isoproterenol, procaineamide,

flecainide, verapamil, and isoproterenol+propranolol had statistically significant effects on human

iPS cells between pre drug loading and the maximum concentration of the drug used in cardiomyocytes derived from human iPS cells $(P<0.05)$. There were no statistically significant differences between the concentrations of drugs that elicited effects in human iPS cells and those that elicited effects in human ES cells (B). 


\section{References}

[1] A. J. Moss, J. McDonald, Unilateral cervicothoracic sympathetic ganglionectomy for the treatment of long QT interval syndrome, N. Engl. J. Med. 285 (1971) 903-4.

[2] A. J. Moss, P. J. Schwartz, R. S. Crampton, E. Locati, E. Carleen E, The long QT syndrome: a prospective international study, Circulation 71 (1985) 17-21.

[3] M. C. Sanguinetti, C. Jiang, M. E. Curran, M.T. Keating, A mechanistic link between an inherited and an acquired cardiac arrhythmia: HERG encodes the IKr potassium channel, Cell 81 (1995) 299- 307.

[4] Q. Wang, J. Shen, I. Splawski, D. L. Atkinson, Z. Z. Li, J. L. Robinson, A. J. Moss, J. A. Towbin, M. T. Keating, SCN5A mutations associated with an inherited cardiac arrhythmia, long QT syndrome, Cell 89 (1995) 805-11.

[5] I. Splawski, J. Shen, K. W. Timothy, M. H. Lehmann, S. Priori, J. L. Robinson, A. J. Moss, P. J. Schwartz, J. A. Towbin, G. H. Vincent, M. T. Keating, Spectrum of mutations in long-QT syndrome genes. KVLQT1, HERG, SCN5A, KCNE1, and KCNE2, Circulation 102 (2000) 1178-85.

[6] I. Splawski, K. W. Timothy, L. M. Sharpe, N. Decher, P. Kumar, R. Bloise, C. Napolitano, P. J. Schwartz, R. M. Joseph, K. Condouris, H. T. Flusberg, S. G. Priori. M. C. Sanguinetti, M. T. 
Keating, $\mathrm{Ca}(\mathrm{V}) 1.2$ calcium channel dysfunction causes a multisystem disorder including arrhythmia and autism, Cell 119 (2004) 19-31.

[7] P. J. Schwartz, S. G. Priori, C. Spazzolini, A, J, Moss, G. M. Vincent, C. Napolitano, I. Denjoy,

P. Guicheneney, G. Breithardt, M. T. Keating, A. A. Wilde, L. Toivonen, W. Zareba, J. L. Robinson,

K. W. Timothy, V. Corfield, D. Wattanasirichaigoon, C. Corbett, W. Haverkamp, E. Schulze-Bahr,

M. H. Lehmann, K. Schwartz, P. Coumel, R. Bloise, Genotype-phenotype correlation in the long-QT syndrome: gene-specific triggers for life-threatening arrhythmias, Circulation 103 (2001) $89-95$.

[8] D. J. Tester, L. B. Cronk, J. L. Carr, V. Schulz, B. A. Salisbury, R. S. Judson, M. J. Ackerman, Allelic dropout in long QT syndrome genetic testing: a possible mechanism underlying. false-negative results, Heart Rhythm 3 (2006) 815-21.

[9] H. Vyas, J. Hejlik, M. J. Ackerman, Epinephrine QT stress testing in the evaluation of congenital long-QT syndrome: diagnostic accuracy of the paradoxical QT response, Circulation 113 (2006) $1385-92$.

[10] K. Takahashi, K. Tanabe, M. Ohnuki, M. Narita, T. Ichisaka, K. Tomoda, S. Yamanaka, Induction of pluripotent stem cells from adult human fibroblasts by defined factors, Cell 131 (2007) $861-872$

[11] I. H. Park, N. Arora,H. Huo,N. Maherali, T. Ahfeldt, A. Shimamura, M. W. Lensch, C. Cowan, 
K. Hochedlinger, G. Q. Dale, Disease-specific induced pluripotent stem cells, Cell 134 (2008) 877886.

[12] J. Q. He, Y. Ma, Y. Lee, J. A. Thomson, T. J. Kamp, Human Embryonic stem cells develop into multiple types of cardiac myocytes, Circ. Res. 93 (2003) 32-39.

[13] M. Reppel, C. Boettinger, J. Hescheler, Beta-adrenergic and muscarinic modulation of human embryonic stem cell-derived cardiomyocytes, Cell. Physiol. Biochem. 14 (2004) 187-196.

[14] C. Xu, S. Polic, N. Rao, M. K. Carpenter, Characterization and enrichment of cardiomyocytes derived from human embryonic stem cells, Circ. Res. 91 (2002) 501-508.

[15] M. R. Rosen, Consequences of the Sicilian Gambit, Eur. Heart J. 16 (1995) Suppl G 32-36

[16] J. Hescheler, M. Halbach, U. Egert, H. Bohlen, B. K. Fleischmann, M. Reppel, Determination of electrical properties of ES cell-derived cardiomyocytes using MEAs, J. Electrocardiol. 37(2004) Suppl 110-116

[17] M. Reppel, F. Pillekamp, K. Brockmeier, M. Matzkies, A. Bekcioglu, T. Lipke, F. Nquemo, H. Bonnemeier, J. Hescheler, The electrocardiogram of human embryonic stem cellderived cardiomyocytes, J. Electrocardiol. 38 (2005) 166-170

[18] M. Reppel, P. Igelmund, U. Egert, F. Juchelka, J. Hescheler, I. Drobinskaya, Effect of Cardioactive Drugs on Action Potential Generation and Propagation in Embryonic Stem Cell-Derived Cardiomyocytes, Cell. Physiol. Biochem. 19 (2007) 213-224 
[19] L. Yang, M. H. Soonpaa, A. D. Adler, T. K. Roepke, S. J. Kattman, M. Kennedy, M. E.

Henckaerts, K. Bonham, G. W. Abbott, R. M. Linden, L, J, Field, G. M. Keller, Human

cardiovascular progenitor cells develop from a $\mathrm{KDR}^{+}$embryonic-stem-cell-derived population,

Nature 453 (2008) 524-528

[20] W. Shimizu, C. Antzelevitch, Cellular Basis for the ECG Features of the LQT1 Form of the

Long-QT Syndrome, Circulation 98 (1998) 2314-2322 
Table 1: Drugs and concentrations

\begin{tabular}{|c|c|c|}
\hline Class & Drugs & Concentration \\
\hline \multirow{2}{*}{$\begin{array}{c}\text { Na channel } \\
\text { blocker }\end{array}$} & procainamide & $1 \times 10^{-5}-1 \times 10^{-3} \mathrm{M}$ \\
\cline { 2 - 3 } & mexiletine & $1 \times 10^{-7}-1 \times 10^{-5} \mathrm{M}$ \\
\cline { 2 - 3 }$\beta$ blocker & flecainide & $1 \times 10^{-7}-1 \times 10^{-5} \mathrm{M}$ \\
\hline $\begin{array}{c}\text { K channel } \\
\text { blocker }\end{array}$ & amiodarone & $1 \times 10^{-7}-3 \times 10^{-5} \mathrm{M}$ \\
\hline $\begin{array}{c}\text { Ca channel } \\
\text { blocker }\end{array}$ & verapamil & $1 \times 10^{-4} \mathrm{M}$ \\
\hline $\begin{array}{c}\alpha, \beta \\
\text { stimulant }\end{array}$ & adrenaline & $5 \times 10^{-7}-5 \times 10^{-5} \mathrm{M}$ \\
\hline$\beta$ stimulant & isoproterenol & $1 \times 10^{-5} \mathrm{M}$ \\
\hline
\end{tabular}


Table 2: comparison with clinical empirical result

\begin{tabular}{|c|c|c|c|c|}
\hline \multirow{2}{*}{ Drugs } & \multicolumn{2}{|c|}{ Result } & \multicolumn{2}{c|}{ Clinical efficacy } \\
\cline { 2 - 5 } & contractility & $\begin{array}{c}\text { beating } \\
\text { frequency }\end{array}$ & contractility & $\begin{array}{c}\text { beating } \\
\text { frequency }\end{array}$ \\
\hline procainamide & $\downarrow$ & $\rightarrow$ & $\downarrow$ & $\rightarrow$ \\
\hline mexiletine & $\rightarrow$ & $\rightarrow$ & $\rightarrow$ & $\rightarrow$ \\
\hline flecainide & $\downarrow$ & $\rightarrow$ & $\downarrow$ & $\rightarrow$ \\
\hline propranolol & $\downarrow$ & $\downarrow$ & $\downarrow$ & $\downarrow$ \\
\hline amiodarone & $\rightarrow$ & $\downarrow$ & $\rightarrow$ & $\downarrow$ \\
\hline verapamil & $\downarrow$ & $\downarrow$ & $\downarrow$ & $\downarrow$ \\
\hline isoproterenol & $\uparrow$ & $\uparrow$ & $\uparrow$ & $\uparrow$ \\
\hline adorenaline & $\uparrow$ & $\uparrow$ & $\uparrow$ & $\uparrow$ \\
\hline
\end{tabular}




\section{Table 3: primers for RT-PCR}

\begin{tabular}{|c|c|c|}
\hline Genes & Direction & Sequences \\
\hline \multirow[t]{2}{*}{ OCT4 (endo) } & Forward & GACAGGGGGAGGGGAGGAGCTAGG \\
\hline & Reverse & СТTСССТССАACCAGTTGCCCCAAAC \\
\hline \multirow[t]{2}{*}{ SOX2 (endo) } & Forward & GGGAAATGGGAGGGGTGCAAAAGAGG \\
\hline & Reverse & TTGCGTGAGTGTGGATGGGATTGGTG \\
\hline \multirow[t]{2}{*}{$C-K I T$} & Forward & ATTCCCAGCCCATGAGTCCTTGA \\
\hline & Reverse & ACACGTGGAACACCAACATCCT \\
\hline \multirow[t]{2}{*}{ Brachyury } & Forward & AAGGTGGATCTTCAGGTAGC \\
\hline & Reverse & CATCTCATTGGTGAGCTCC \\
\hline \multirow[t]{2}{*}{$K D R$} & Forward & AAAACCTTTTGTTGCTTTTGG \\
\hline & Reverse & GAAATGGGATTGGTAAGGATG \\
\hline \multirow[t]{2}{*}{$N k x 2.5$} & Forward & GCGATTATGCAGCGTGCAATGAGT \\
\hline & Reverse & AACATAAATACGGGTGGGTGCGTG \\
\hline \multirow[t]{2}{*}{$T B X 5$} & Forward & AAATGAAACCCAGCATAGGAGCTGGC \\
\hline & reverse & ACACTCAGCCTCACATCTTACCCT \\
\hline \multirow[t]{2}{*}{$M E F 2 c$} & Forward & TTTAACACCGCCAGCGCTCTTCACCTTG \\
\hline & reverse & TCGTGGCGCGTGTGTTGTGGGTATCTCG \\
\hline \multirow[t]{2}{*}{$M L C 2 a$} & Forward & ACATCATCACCCACGGAGAAGAGA \\
\hline & reverse & ATTGGAACATGGCCTCTGGATGGA \\
\hline \multirow[t]{2}{*}{$M Y H C B$} & Forward & CTGGAGGCCGAGCAGAAGCGCAACG \\
\hline & reverse & GTCCGCCCGCTCCTCTGCCTCATCC \\
\hline \multirow[t]{2}{*}{ HCN4 } & Forward & GGTGTCCATCAACAACATGG \\
\hline & reverse & TGTACTGCTCCACCTGCTTG \\
\hline \multirow[t]{2}{*}{$S C N 5 A$} & Forward & CCTAATCATCTTCCGCATCC \\
\hline & reverse & TGTTCATCTCTCTGTCCTCATC \\
\hline \multirow[t]{2}{*}{ Kir2.1 } & Forward & GACCTGGAGACGGACGAC \\
\hline & reverse & AGCCTGGAGTCTGTCAAAGTC \\
\hline \multirow[t]{2}{*}{$K v 4.3$} & Forward & GCCAGTCCCTGTGATTGTTT \\
\hline & reverse & СTCCATGCAGTTCTGCTCAA \\
\hline \multirow[t]{2}{*}{$H E R G$} & Forward & TCCAGCGGCTGTACTCGGGC \\
\hline & reverse & TGGACCAGAAGTGGTCGGAGAACTC \\
\hline \multirow[t]{2}{*}{$C A C N A 1 C$} & Forward & AACATCAACAACGCCAACAA \\
\hline & reverse & AGGGCAGGACTGTCTTCTGA \\
\hline \multirow[t]{2}{*}{$G A P D H$} & Forward & CACCAGGGCGCTTTTAACTCTG \\
\hline & reverse & ATGGTTCACACCCATGCGAAC \\
\hline
\end{tabular}


A

Figure 1

0
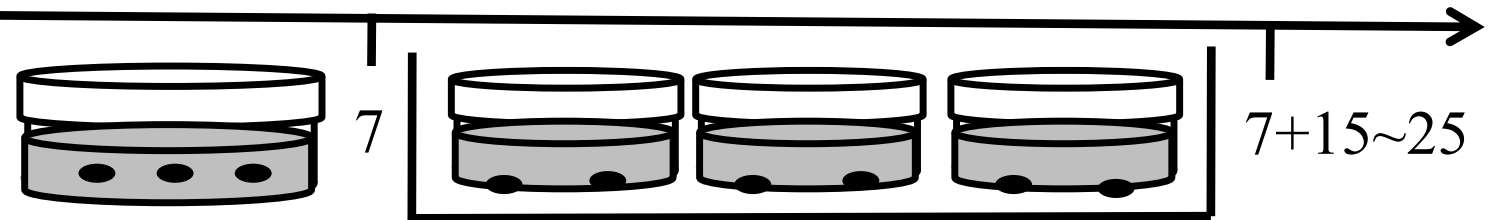

Suspension culture

Plating EBs

Emergence of bFGF 5ng/ml on gelatin coated dish beating colonies

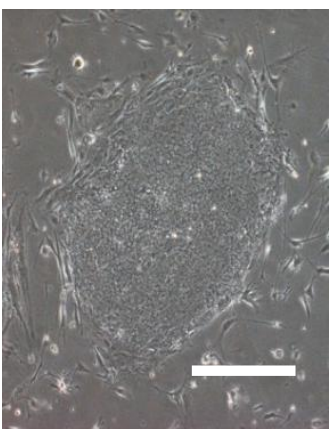

Undifferentiated colony

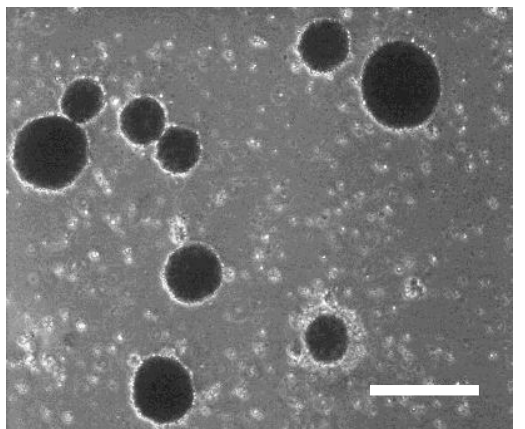

Embryoid bodies (day7)

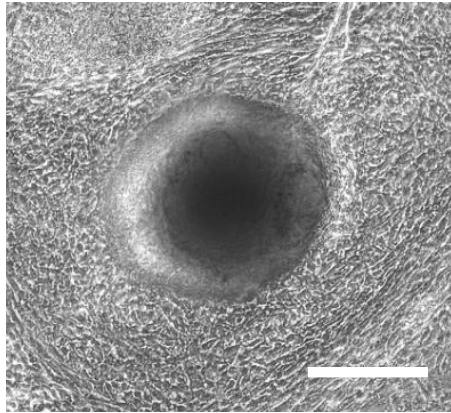

Contractile colony

B

Sox2(endo)

OCT4(endo)

Brachyury

$K D R$

$T B X 5$

GAPDH

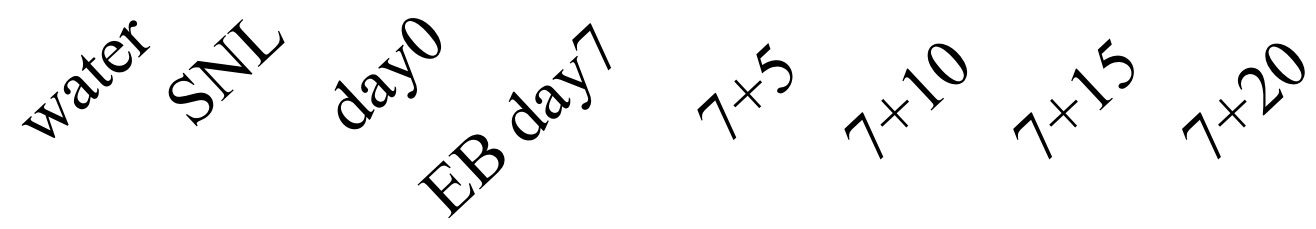


A

Figure 2

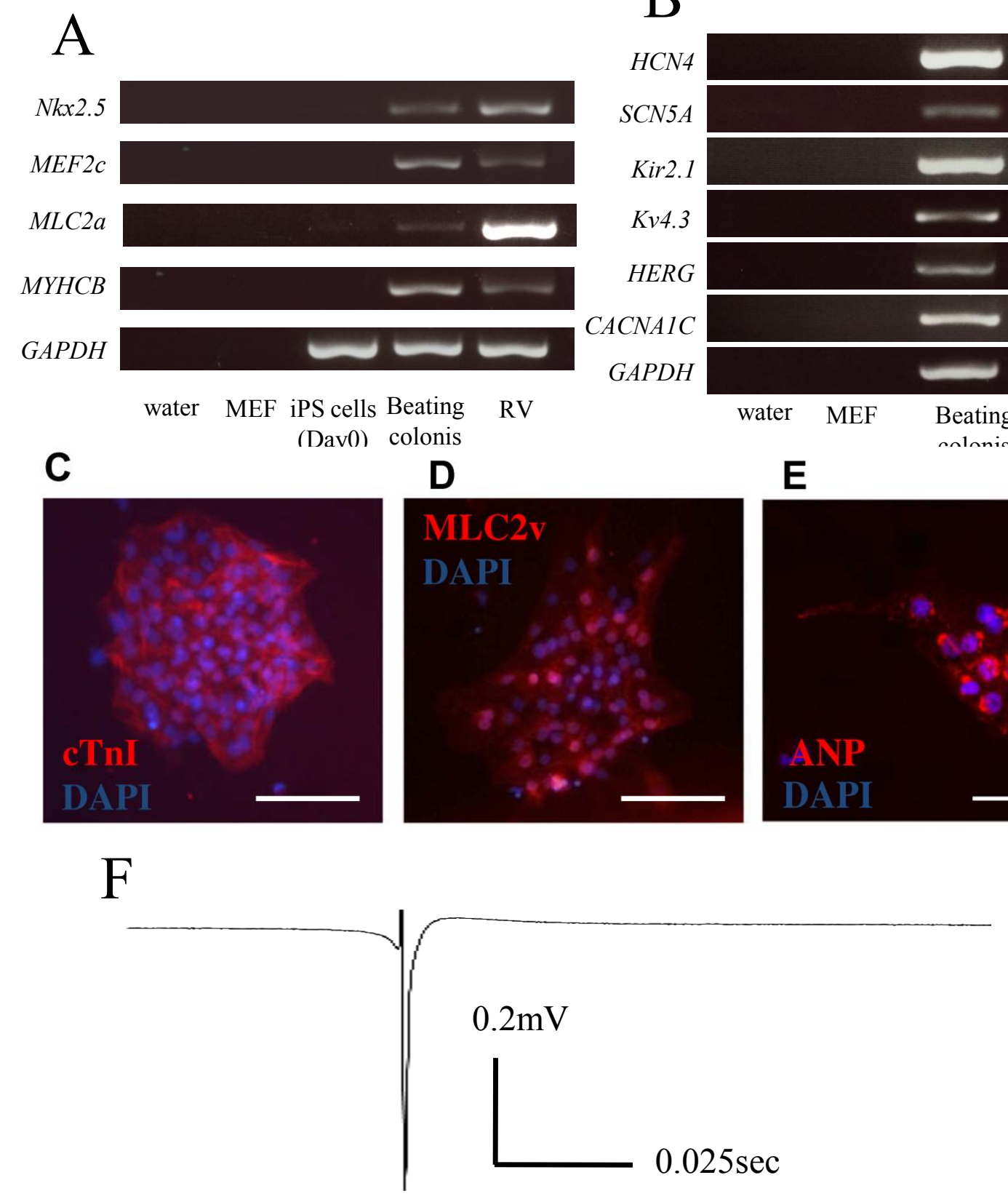


Figure 3
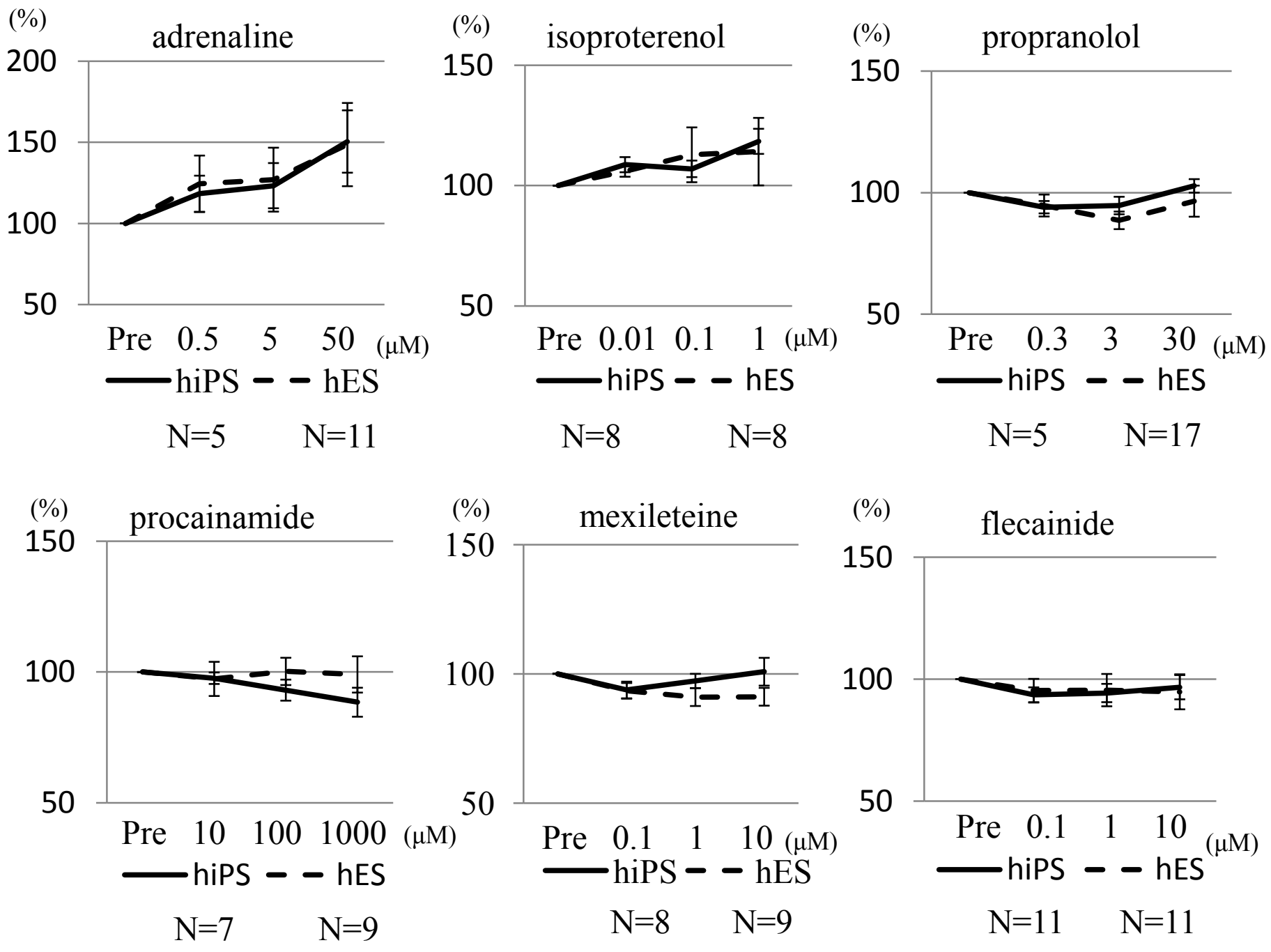

Pre $0.1110(\mu \mathrm{M})$
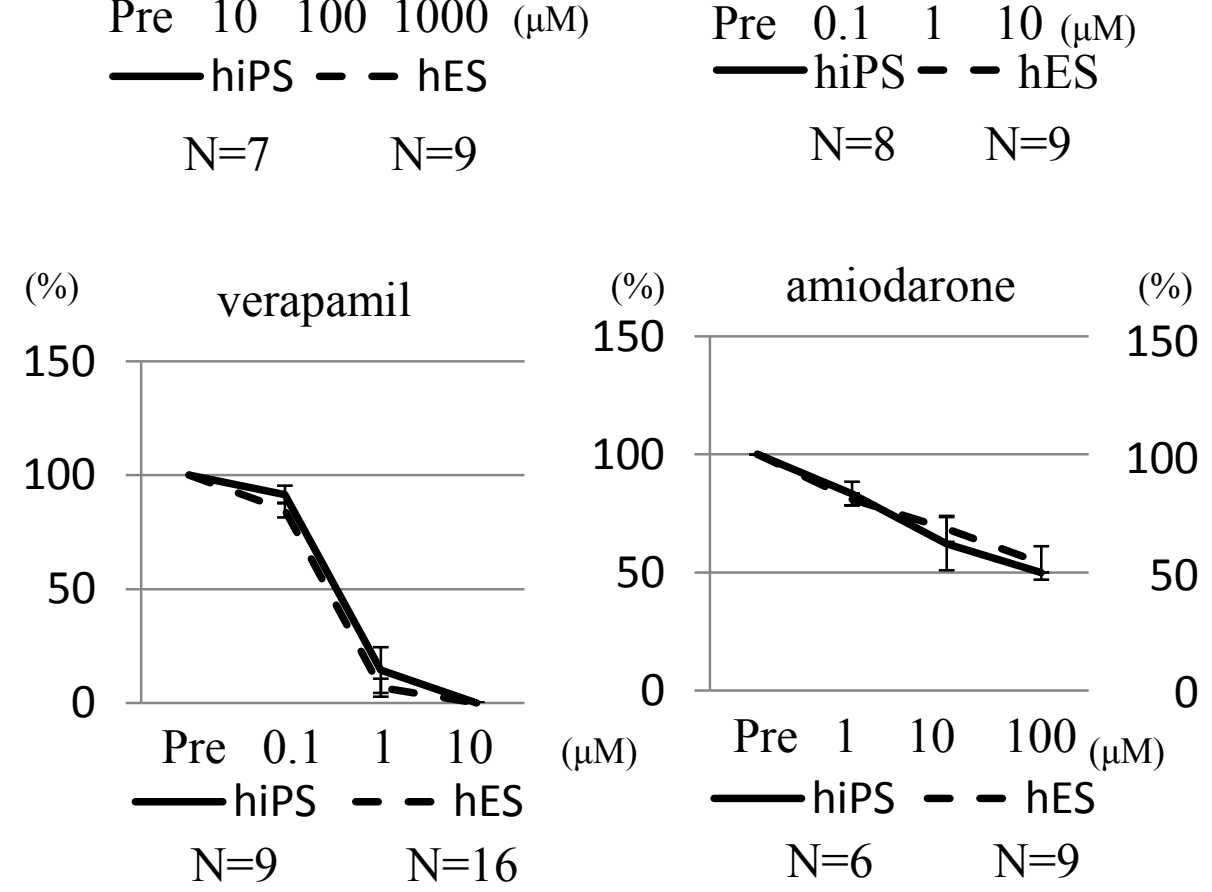

isoproterenol $1 \mu \mathrm{M}$

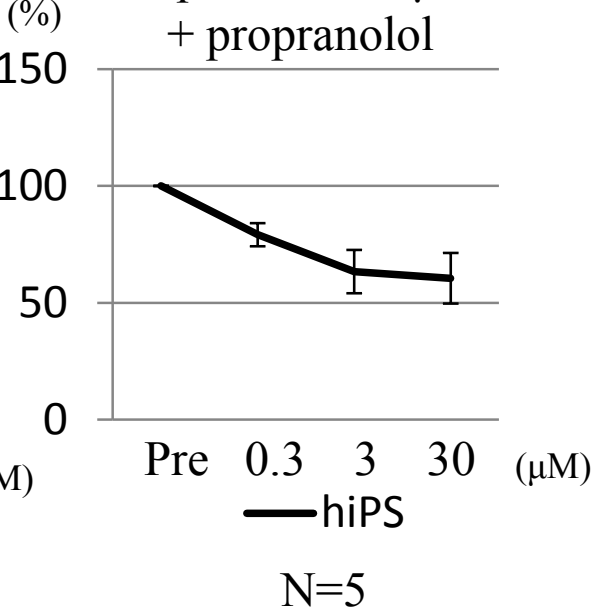


A

Figure 4

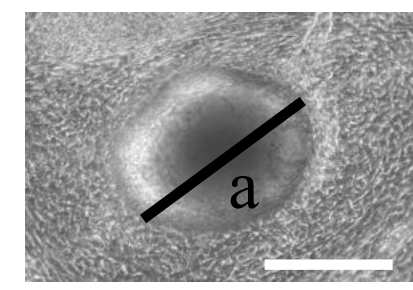

Diastolic phase

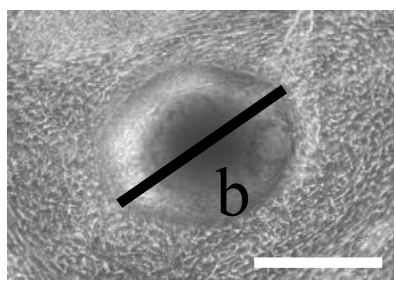

Systolic phase

Contractility Index $=a-b / a$

B
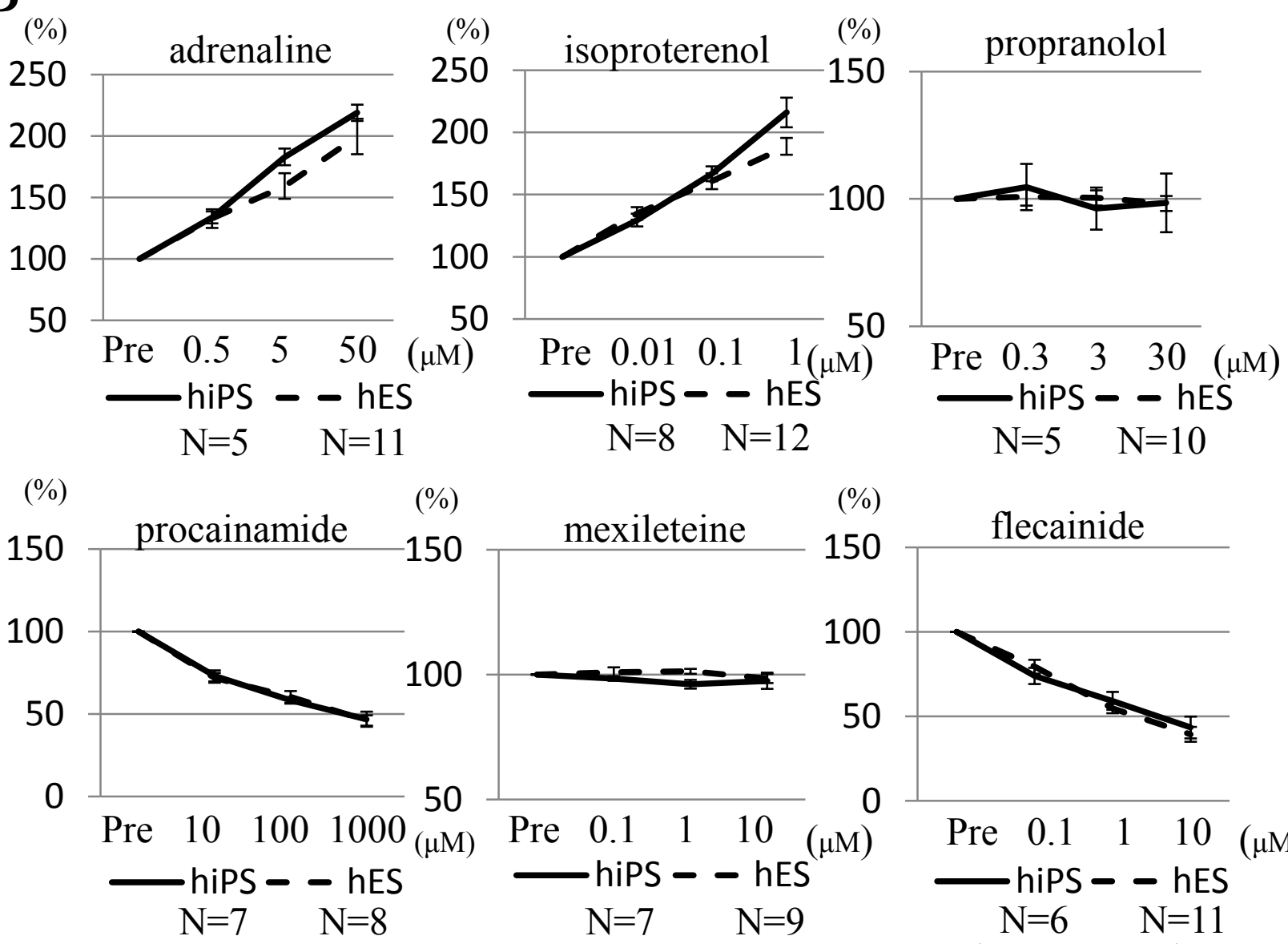

(\%)
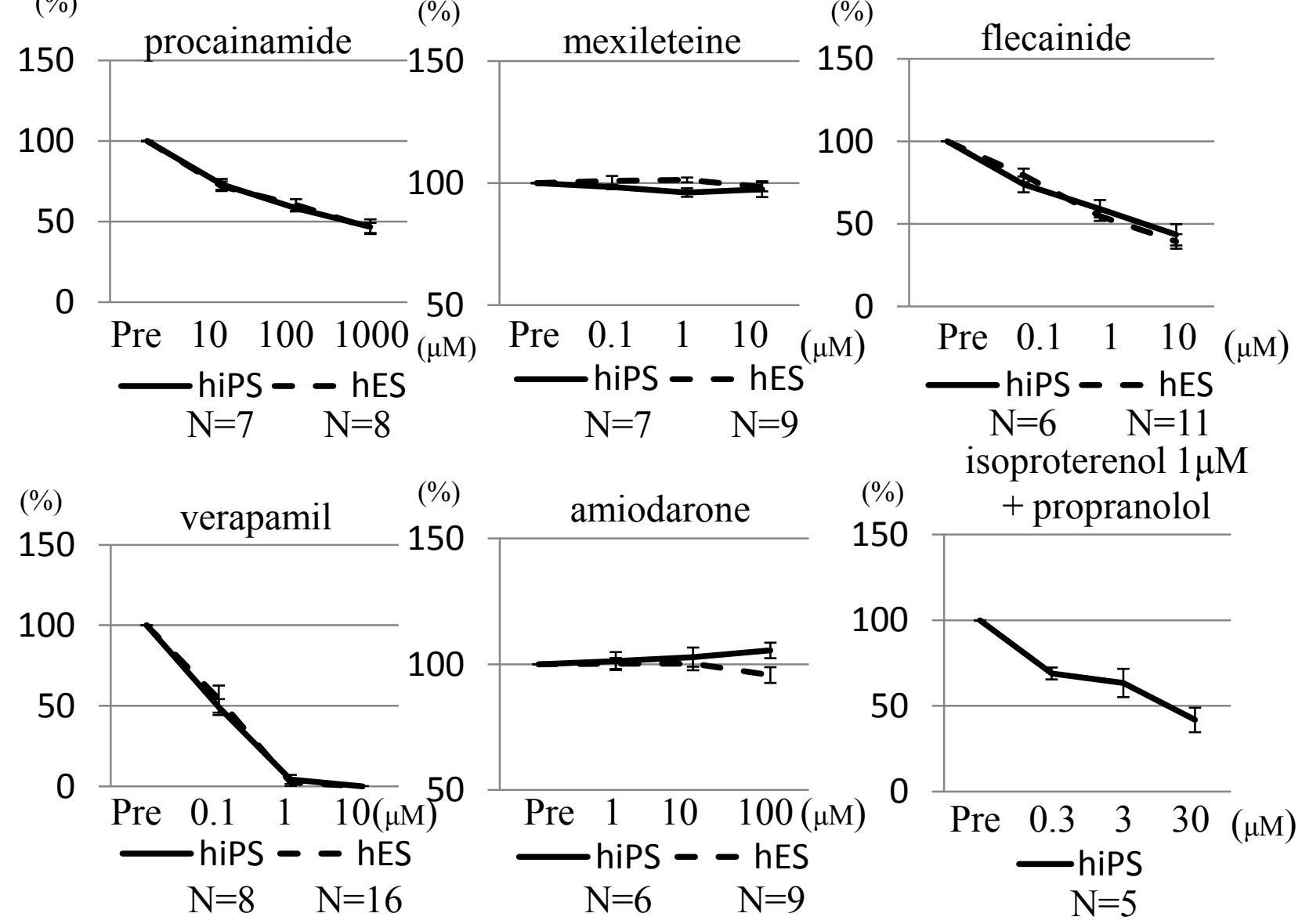